\title{
ÍNDICES DE ÁREA VERDE E COBERTURA VEGETAL PARA AS PRAÇAS DO MUNICÍPIO DE VINHEDO, SP ${ }^{1}$
}

\author{
Isabel Cristina Fialho Harder ${ }^{2}$, Roberval de Cássia Salvador Ribeiro ${ }^{3}$ e Armando Reis Tavares ${ }^{4}$
}

\begin{abstract}
RESUMO - Neste estudo, objetivou-se a obtenção, para o Município de Vinhedo (SP), de índices que auxiliem a indicação da ocupação dos espaços urbanos pela vegetação. Foi realizado o levantamento das praças localizadas dentro dos bairros e das árvores (altura, diâmetro da copa e circunferência à altura do peito) contidas nessas praças. Os índices de área verde calculados foram: Índice de Áreas Verdes Total (IAVT), Índice de Áreas Verdes para Parque da Vizinhança (IAVPV), Índice de Áreas Verdes para Parque de Bairro (IAVPB), Índice de Áreas Verdes Utilizáveis (IAVU), Índice de Área Verde por Bairro (AVB) e Índice de Cobertura Vegetal (ICV). O Município de Vinhedo apresentou pouca variação entre os índices IAVT $=2,19 \mathrm{~m}^{2}$ e IAVU $=1,95 \mathrm{~m}^{2}$, indicando que a maioria das áreas verdes era utilizável. O IAVT de Vinhedo estava abaixo do mínimo de $15 \mathrm{~m}^{2} / \mathrm{habitante}$ para áreas verdes públicas destinadas à recreação, sugerido pela Sociedade Brasileira de Arborização Urbana.
\end{abstract}

Palavras-chave: Índice de área verde e arborização urbana.

\section{GREEN AREA AND VEGETATION COVER INDEXES FOR COMMONS IN THE CITY OF VINHEDO, SP}

\begin{abstract}
This research was carried out to study, in the city of Vinhedo (SP), indexes that indicate the vegetation occupation in urban spaces. Data were collected by locating the commons in the neighborhoods and the tree measures (height, diameter and circumference at breast height), in those commons. The calculated indexes were Total Green Area Index (IAVT), Green Area Index for Near Neighborhood Park (IAVPV), Green Area Index for Neighborhood Park (IAPVPB), Usable Green Area Index (IAVU), Green Area Index for Neighborhoods $(A V B)$ and Vegetation Cover Index (ICV). The city of Vinhedo showed few variation between the indexes IAVT $=2.19 \mathrm{~m}^{2}$ and IAVU $=1.95 \mathrm{~m}^{2}$ indicating that most of the green areas are usable. Vinhedo's IAVT is below the minimum of $15 \mathrm{~m}^{2} /$ inhabitant for public recreation in green areas, suggested by the Brazilian Society for Urban Forestation.

Keywords: Green Area Ratio and Urban forestry.
\end{abstract}

\section{INTRODUÇÃ̃O}

“Áreas verdes" é um termo que se aplica a diversos tipos de espaços urbanos que têm em comum o fato de serem abertos, acessíveis; relacionados com saúde e recreação ativa e passiva, proporcionaram interação das atividades humanas com o meio ambiente (DEMATTÊ, 1997). Segundo Llardent (1982), áreas, zonas, espaços ou equipamentos verdes são espaços livres onde predominam áreas plantadas de vegetação, correspondendo, em geral, ao que se conhece como parques, jardins ou praças.

\footnotetext{
${ }^{1}$ Recebido em 07.07.2004 e aceito para publicação em 10.11.2005.

${ }^{2}$ Programa de Pós-Graduação em Fitotecnia pela Escola Superior de Agricultura Luiz de Queiroz/USP, Av. Luiz Pereira dos Santos, 1.500, 13214-820 Jundiaí-SP. E-mail:<isabo@uol.com.br>.

${ }_{3}^{3}$ Departamento de Produção Vegetal daESALQ-USP, Av.Pádua Dias, 11, Cx. P.9, 13418-900 Piracicaba-SP.E-mail:<rcsribei@esalq.usp.br>.

${ }^{4}$ Instituto de Botânica/IBt, Cx. P. 4005, 01061-970 São Paulo-SP. E-mail: <napias@ pop.com.br>.
} 
Praças são pontos de encontro cuja principal função é incentivar a vida comunitária; são áreas verdes com dimensões, em geral, entre $100 \mathrm{~m}^{2}$ e 10 ha. Porém, não se pode padronizar a praça, quanto ao tamanho, sem conhecer antes o seu entorno (DEMATTÊ, 1997; PORTO ALEGRE, 2001).

Segundo Nucci (2001), uma questão muito discutida quando se fala em vegetação urbana diz respeito ao índice de áreas verdes. Muitas cidades procuram aumentar seus índices colocando todo espaço não construído como área verde e considerando a projeção das copas das árvores sobre as calçadas (CAVALHEIRO e NUCCI, 1998). Enquanto alguns trabalhos envolvem o cadastramento de árvores para elaboração de bancos de dados informatizados ou da avaliação das condições fitossanitárias da vegetação, existem aqueles que se preocupam com a avaliação da utilização do espaço pelo público, do perfil dos usuários e dos aspectos perceptivos em relação à arborização (OLIVEIRA, 1996). Nucci (2001) afirmou que, para calcular o índice de área verde, devem ser consideradas somente as áreas verdes públicas localizadas na zona urbana e ligadas ao uso direto da população residente nessa área.

A quantificação da arborização urbana tem sido realizada através de indicadores dependentes e independentes da demografia, expressos, respectivamente, em termos de superfície de área verde/ habitante (IAV = Índices de Áreas Verdes) ou porcentual do solo ocupado pela arborização (PAV = Porcentual de Áreas Verdes) (OLIVEIRA, 1996). Cavalheiro e Del Picchia (1992) discutiram a existência do índice de $12 \mathrm{~m}^{2}$ de área verde/habitante considerado ideal, arraigado e difundido no Brasil e atribuído à ONU, OMS ou FAO. Os referidos autores afirmaram que esse índice não é conhecido por aquelas instituições e supõem que deve se referir somente às categorias de parques de bairro e distritais/setoriais, ou seja, áreas públicas com possibilidades de lazer ao ar livre. A Sociedade Brasileira de Arborização Urbana (SBAU) propôs como índice mínimo para áreas verdes públicas destinadas à recreação o valor de 15 m²/habitante (SBAU, 1996).

A questão controvertida da categorização e definição de áreas verdes adotadas por vários autores brasileiros torna ainda mais complexa uma avaliação sobre aquilo que se poderia chamar de "índices mínimos de cobertura vegetal" (OLIVEIRA, 1996).

R. Árvore, Viçosa-MG, v.30, n.2, p.277-282, 2006
Jantsen (1973), citado por Cavalheiro e Del Picchia (1992), propôs que as áreas verdes, além de quantitativamente, deveriam ser classificadas de acordo com a faixa etária, o tamanho mínimo do espaço, a distância da residência etc. Segundo Nucci (2001), outros índices devem ser calculados, como: índice de cobertura vegetal, em que se consideram todas as manchas de vegetação, por exemplo as copas das árvores; e índice de áreas verdes utilizáveis, quando a área verde não apresenta condições de uso e, após a qualificação das áreas verdes, dever-se-ia recalcular o índice de áreas verdes, indicando a quantidade delas utilizáveis pela comunidade de acordo com suas qualificações.

Este estudo objetivou caracterizar, de maneira quantitativa, a arborização das praças de Vinhedo, SP, gerando índices de áreas verdes que possam fornecer subsídios para o planejamento e aplicação de medidas mitigadoras em condições tropicais.

\section{MATERIAL E MÉTODOS}

\subsection{Caracterização do local}

O Município de Vinhedo localiza-se a $23^{\circ} 01^{\prime} 46^{\prime \prime}$ de latitude sul e $46^{\circ} 58^{\prime} 30^{\prime \prime}$ de longitude oeste, tem área de $82 \mathrm{~km}^{2}$ e está situado na região sudeste do Estado de São Paulo, a 76 km da capital. Apresenta topografia de conformação suave, rebaixada, com altitudes variando de 700 a 900 m. O clima, segundo a classificação de Köppen, é Cwa, ou seja, clima subtropical com duas estações definidas, úmida e quente. Sua pluviosidade média anual é de 1.404 mm (VINHEDO, 2000). Os solos da região são do tipo LVA22, ou seja, Latossolo Vermelho-Amarelo, com boa drenagem interna, além de Cambissolos Háplicos e Distróficos com textura média e argilosa, sendo ambos com horizonte A moderado e proeminente (OLIVEIRA et al., 1999; OLIVEIRA, 1999).

No censo do Instuto Brasileiro de Geografia e Estatística de 2002 (IBGE), Vinhedo apresenta população de 47.215 habitantes. Desses, 46.174 residem na área urbana, 1.041 na área rural, sendo o restante uma população flutuante de aproximadamente 15.000 pessoas. Apresenta densidade demográfica de 522 habitantes por $\mathrm{km}^{2}$. A cidade possui 31 bairros, sendo que oito apresentaram áreas destinadas a praças, num total de 22 delas. 


\subsection{Diagnóstico}

Os levantamentos foram feitos no perímetro urbano da cidade de Vinhedo, excetuando-se os condomínios, as áreas de parques (Parque da Uva, Represa e Cristo) e de preservação de mananciais.

Os dados foram coletados durante os meses de abril e maio de 2000. Realizou-se o inventário da vegetação arbórea, no qual foram considerados apenas os indivíduos com circunferência acima do peito (CAP) - 1,30 m acima de $10 \mathrm{~cm}$, usando-se de fita métrica, em que foram coletados os seguintes dados: CAP, altura e diâmetro de copa. Para medir o diâmetro de copa, foram consideradas duas medidas, uma no sentido nortesul e outra no sentido leste-oeste, visando verificar a uniformidade da copa quanto ao seu desenvolvimento e levantar o índice de cobertura arbórea.

Para a localização das áreas, foi consultada a planta do município de 1997.

\subsection{Caracterização dos bairros}

A caracterização dos espaços livres em parque de vizinhança ou parque de bairro seguiu a metodologia adotada por Jantzen (1973), citado por Cavalheiro e Del Picchia (1992). Os bairros foram codificados com a letra B e as praças, com as letras B e P, em que B é o bairro onde se localiza a praça e $\mathrm{P}$, a área inventariada (Tabela 1).

Para a classificação das áreas, considerou-se apenas o tamanho das praças e não foram calculados os índices de área por habitante, por não terem sido encontrados dados sobre a população de cada bairro.

\section{4. Índices calculados}

\subsection{1. Índice de áreas verdes (IAV)}

Para calcular o índice de áreas verdes da cidade de Vinhedo, foi considerado o somatório das áreas totais das praças, expresso em metro quadrado, dividido pelo número de habitantes da área urbana. As áreas dos canteiros sem arborização não foram consideradas.

\subsubsection{1. Índice de áreas verdes total (IAVT)}

$$
\text { IAVT }=\frac{\sum \text { das áreas totais das praças }}{\text { n. de habitantes da área urbana }}
$$

Tabela 1 - Codificação e denominação dos bairros e praças existentes na cidade de Vinhedo, 2002

Table 1 - Code and denomination of neighborhoods and commons in the city of Vinhedo, 2002

\begin{tabular}{|c|c|c|c|}
\hline \multicolumn{2}{|r|}{ BAIRRO } & \multicolumn{2}{|c|}{ PRAÇA } \\
\hline Código & Nome & Código & Nome \\
\hline \multirow[t]{5}{*}{ B 1} & João XXIII & B 1P1 & Uderico Reichel \\
\hline & & B 1 P2 & Padre Luiz Sais \\
\hline & & B 1P3 & sem nome \\
\hline & & B 1P4 & Vila João XXIII \\
\hline & & B 1P5 & Uderico Reichel \\
\hline \multirow[t]{2}{*}{ B2 } & Aquário & $\mathrm{B} 2 \mathrm{P} 1$ & Aquário \\
\hline & & $\mathrm{B} 2 \mathrm{P} 2$ & sem nome \\
\hline \multirow[t]{2}{*}{ B3 } & Santa Rosa & B3P1 & $\begin{array}{c}\text { Dom Martinho } \\
\text { Albert Roth }\end{array}$ \\
\hline & & B 3P2 & Da Vitória \\
\hline \multirow[t]{2}{*}{ B4 } & Vila Planalto & B 4P1 & Biquinha \\
\hline & & B4P2 & $\begin{array}{l}\text { Comendador } \\
\text { Paulo Storani }\end{array}$ \\
\hline \multirow[t]{5}{*}{ B5 } & Centro & B 5P1 & De Sant'Ana \\
\hline & & B 5P2 & $\begin{array}{c}\text { Centro de } \\
\text { Convivência }\end{array}$ \\
\hline & & B5P3 & Corazzari \\
\hline & & B5P4 & sem nome \\
\hline & & B5P5 & sem nome \\
\hline \multirow[t]{4}{*}{ B6 } & Jardim Três Irmãos & B 6P1 & $\begin{array}{c}\text { Prefeito Jair } \\
\text { Mendes de Barros }\end{array}$ \\
\hline & & B6P2 & sem nome \\
\hline & & B6P3 & sem nome \\
\hline & & B6P4 & sem nome \\
\hline B7 & Jardim Von Zuben & B 7P1 & sem nome \\
\hline B8 & Capela & B 8P1 & $\begin{array}{c}\text { Centro de Lazer do } \\
\text { Trabalhador } \\
\text { "Aurora Sudário" }\end{array}$ \\
\hline
\end{tabular}

\subsubsection{2. Índice de áreas verdes para parque de vizinhança (IAVPV)}

IAVPV $=\frac{\sum \text { das áreas de parques de vizinhança }}{\mathrm{n} \cdot \text { de habitantes da área urbana }}$

\subsubsection{3. Índice de áreas verdes para parque de bairro (IAVPB)}

IAVPB $=\frac{\sum \text { das áreas de parques de bairro }}{\text { n. de habitantes da área urbana }}$

\subsubsection{4. Índice de áreas verdes utilizáveis (IAVU)}

O cálculo do índice de áreas verdes utilizáveis foi obtido por meio da seguinte fórmula:

IAVU $=\frac{\sum \text { das áreas }(\mathrm{m} 2) \text { da praças totalmente utilizáveis }}{\text { n. de habitantes da área urbana }}$

R. Árvore, Viçosa-MG, v.30, n.2, p.277-282, 2006 
As praças foram classificadas em totalmente utilizáveis, parcialmente utilizáveis e sem condições de uso: totalmente utilizáveis: com presença de bancos, gramados, canteiros, arbustos, limpeza e construções em bom estado de conservação; parcialmente utilizáveis: com presença de bancos, gramados, canteiros, arbustos, limpeza e construções em estado razoável de conservação; e sem condições de uso: sem presença de bancos, gramados, canteiros, arbustos, limpeza e construções em estado ruim de conservação.

\subsubsection{5. Índice de área verde por bairro (AVB)}

$\mathrm{IAVB}=\frac{\sum \text { das áreas }\left(\mathrm{m}^{2}\right) \text { da praças de cada bairro }}{\text { área total do bairro }}$

\subsection{2. Índice de cobertura vegetal (ICV)}

$\mathrm{ICV}=\frac{\sum \text { das áreas de copa }}{\mathrm{n} . \text { de habitantes da área urbana }}$

\section{RESULTADOS E DISCUSSÃO}

Quanto aos índices urbanísticos, obteve-se, na cidade de Vinhedo, o seguinte resultado: $86,36 \%$ das praças enquadravam-se na categoria "parque de vizinhança", e 13,64\% das áreas encaixavam-se na categoria "parque de bairro".

A classificação por categoria de cada praça está listada na Tabela 2.

Na Tabela 3, observa-se a área total de parques de vizinhança e de bairro distribuídos nos diferentes bairros (B1 a B8) levantados.

A cidade de Vinhedo possuía $29.906 \mathrm{~m}^{2}$ de parque de vizinhança e $71.400 \mathrm{~m}^{2}$ de parque de bairro, totalizando $101.360 \mathrm{~m}^{2}$ de áreas verdes. Os bairros B2 e B7 apresentavam quantidade pouco significativa de parques de vizinhança e B8 não continha nenhum parque de vizinhança.

A área total de copa encontrada nas praças do Município de Vinhedo foi de $25.428,45 \mathrm{~m}^{2}$. No município foram obtidos o ICV de $0,55 \mathrm{~m}^{2}$ de copa em praças/ habitantes da área urbana e o IAVT de $2,19 \mathrm{~m}^{2} \mathrm{de}$ praça/habitante da área urbana.

Oliveira (1996) encontrou o índice de áreas verdes médio representado pela arborização de rua de 2,65 $\mathrm{m}^{2} /$ habitante de cobertura vegetal de áreas verdes públicas, na cidade de São Carlos (SP), porém, analisando separadamente as áreas estudadas, os índices variaram de 0,37 a 10,59 $\mathrm{m}^{2} /$ habitante. Segundo ele, a inexistência de um conceito aceito de áreas verdes para as diferenças nos métodos de estimativa de IAV dificulta as informações geradas na São Carlos com relação a outras cidades brasileiras.

Tabela 2 - Área total e classificação por categoria das praças existentes nos diferentes bairros da cidade de Vinhedo (SP), 2002

Table 2 - Total Area and classification by category of the existent commons in the different neighborhoods in the city of Vinhedo (SP), 2002

\begin{tabular}{lcc}
\hline Praças & Área total $\left(\mathrm{m}^{2}\right)$ & Categoria * \\
\hline B1P1 & 450 & Parque de vizinhança \\
B1P2 & 400 & Parque de vizinhança \\
B1P3 & 750 & Parque de vizinhança \\
B1P4 & 1000 & Parque de vizinhança \\
B1P5 & 400 & Parque de vizinhança \\
B2P1 & 32000 & Parque de bairro \\
B2P2 & 800 & Parque de vizinhança \\
B3P1 & 2700 & Parque de vizinhança \\
B3P2 & 242 & Parque de vizinhança \\
B4P1 & 594 & Parque de vizinhança \\
B4P2 & 4000 & Parque de vizinhança \\
B5P1 & 2250 & Parque de vizinhança \\
B5P2 & 10000 & Parque de bairro \\
B5P3 & 700 & Parque de vizinhança \\
B5P4 & 4000 & Parque de vizinhança \\
B5P5 & 6000 & Parque de vizinhança \\
B6P1 & 1700 & Parque de vizinhança \\
B6P2 & 540 & Parque de vizinhança \\
B6P3 & 1600 & Parque de vizinhança \\
B6P4 & 530 & Parque de vizinhança \\
B7P1 & 1250 & Parque de vizinhança \\
B8P1 & 29400 & Parque de bairro \\
\hline
\end{tabular}

* Segundo classificação de Jantzen (1973), citada por Cavalheiro e Del Picchia (1992).

Tabela 3 - Áreas das praças classificadas em parques de vizinhança e de bairro, nos diferentes bairros estudados na cidade de Vinhedo (SP), 2002

Table 3 - Commons areas classified as near parks or neighborhood parks, in different neighborhoods studied in the city of Vinhedo (SP), 2002

\begin{tabular}{cccc}
\hline Bairro & $\begin{array}{c}\text { Parque de } \\
\text { vizinhança }\left(\mathrm{m}^{2}\right)\end{array}$ & $\begin{array}{c}\text { Parque de } \\
\text { bairro }\left(\mathrm{m}^{2}\right)\end{array}$ & $\begin{array}{c}\text { Área total } \\
\left(\mathrm{m}^{2}\right)\end{array}$ \\
\hline B1 & 3000 & 0 & 3000 \\
B2 & 800 & 32000 & 32800 \\
B3 & 2942 & 0 & 2942 \\
B4 & 4594 & 0 & 4594 \\
B5 & 12950 & 10000 & 22950 \\
B6 & 4370 & 0 & 4370 \\
B7 & 1250 & 0 & 1250 \\
B8 & 0 & 29400 & 29400 \\
\hline
\end{tabular}


Carvalho (2001) comentou que, em Lavras, MG, o índice de áreas verdes indicou a existência de 0,34 $\mathrm{m}^{2} /$ habitante, e Lima (1993) encontrou o valor de 2,2 $\mathrm{m}^{2} /$ habitante na cidade de Piracicaba, SP, sendo que o valor verificado em Vinhedo estava acima do de Lavras e praticamente igual ao de Piracicaba. Milano (1984) obteve o índice de $3,06 \mathrm{~m}^{2} /$ habitante para arborização de ruas de Curitiba, PR.

Segundo Martins Júnior (2002), a cidade de Goiânia tem $100,25 \mathrm{~m}^{2}$ de área verde por habitante (potencial e, ou, efetivamente implantados), divididos nas seguintes categorias: área verde particular $(44,84 \%)$, equipamento público $(11,68 \%)$, parque linear $(11,68 \%)$, parque $(10,95 \%)$, espaço livre público $(2,72 \%)$, praça $(2,65 \%)$, verde de acompanhamento viário $(2,21 \%)$, jardim de representação $(1,47 \%)$ e cemitério $(0,52 \%)$. Os valores de área verde representados por praças $(2,72 \%$ equivalente a 100,25 $\mathrm{m}^{2}$ /habitante) na cidade de Goiânia são bastante próximos daqueles obtidos em Vinhedo. Considerando esse índice médio, a cidade de Vinhedo apresenta índice duas vezes maior. Vale ressaltar que os parques públicos não foram computados.

Pode-se observar que o índice de Vinhedo está muito aquém do mínimo de $15 \mathrm{~m}^{2} /$ habitante para áreas verdes públicas destinadas à recreação, conforme sugerido pela SBAU (1996).

No Município de Vinhedo foi obtido o IAVPV de $0,65 \mathrm{~m}^{2}$ de parque de vizinhança/habitante da área urbana. Lima et al. (1993) encontraram o valor de $0,54 \mathrm{~m}^{2} /$ habitante em Piracicaba e Sousa et al. (1992), o valor de 1,96 $\mathrm{m}^{2} /$ habitante em Botucatu, SP, para parque de vizinhança. Lavras, MG, apresentou o valor de $0,12 \mathrm{~m}^{2} /$ habitante para parques de vizinhança (CARVALHO, 2001). Vinhedo teve um índice aquém do da cidade de Botucatu.

No Município de Vinhedo foi obtido o IAVPB de $1,55 \mathrm{~m}^{2}$ de parque de bairro/habitante da área urbana. Lima et al. (1993) encontraram o valor de $0,60 \mathrm{~m}^{2} /$ habitante em Piracicaba e Sousa et al. (1992), o valor de 0,77 $\mathrm{m}^{2} /$ habitante em Botucatu, para parque de bairro. Carvalho (2001) obteve $0,19 \mathrm{~m}^{2} /$ habitante para parque de bairro em Lavras. Vinhedo apresentou um índice bem superior aos das três cidades.

Os índices de área verde por bairro encontramse na Tabela 4.
Tabela 4 - Índice de área verde por bairro obtido nas praças dos diferentes bairros da cidade de Vinhedo (SP), 2000

Table 4 - Green Area Index per Neighborhood obtained in the commons of different neighborhoods in the city of Vinhedo (SP), 2000

\begin{tabular}{lccc}
\hline Bairro & $\begin{array}{c}\text { Área das } \\
\text { praças }\left(\mathrm{m}^{2}\right)\end{array}$ & $\begin{array}{c}\text { Área do } \\
\text { bairro }\left(\mathrm{m}^{2}\right)\end{array}$ & $\begin{array}{c}\text { IAVB } \\
\left(\mathrm{m}^{2}\right)\end{array}$ \\
\hline B1 & 3000 & 800000 & 0,0038 \\
B2 & 32800 & 765000 & 0,0429 \\
B3 & 2942 & 750000 & 0,0039 \\
B4 & 4594 & 302500 & 0,0152 \\
B5 & 22950 & 300000 & 0,0765 \\
B6 & 4370 & 490000 & 0,0089 \\
B7 & 1250 & 906250 & 0,0014 \\
B8 & 29400 & 2718750 & 0,0108 \\
\hline
\end{tabular}

Os bairros B2, B4 e B5 mostraram os maiores índices de área verde por bairro, sendo que esses bairros possuíam vegetação consolidada. Os bairros B1, B3 e B7 exibiram índices com valores baixos, tendendo a zero. Já Vinhedo apresentou índice de $0,1633 \mathrm{~m}^{2} \mathrm{de}$ área verde por bairro.

\section{CONCLUSÕES}

O Município de Vinhedo, SP, apresentou pouca variação entre os índices IAVT $=2,19 \mathrm{~m}^{2}$ e IAVU $=$ $1,95 \mathrm{~m}^{2}$, indicando que a maioria das áreas verdes era utilizável.

O valor do índice de áreas verdes encontrado em Vinhedo estava acima do da cidade de Lavras, praticamente igual ao de Piracicaba e aquém do da cidade de Botucatu, além de apresentar índice duas vezes maior que a média de 1,198 m² , obtida em 291 municípios.

O IAVT de Vinhedo estava muito aquém do mínimo de $15 \mathrm{~m}^{2} /$ habitante para áreas verdes públicas destinadas à recreação, conforme sugerido pela Sociedade Brasileira de Arborização Urbana (SBAU, 1996).

\section{REFERÊNCIAS BIBLIOGRÁFICAS}

CARVALHO, L.M. Áreas verdes da cidade de Lavras/MG: caracterização, usos e necessidades. 2001. 115f. Dissertação (Mestrado em Fitotecnia) - Universidade Federal de Lavras, Lavras, 2001.

CAVALHEIRO, F.; NUCCI, J.C. Espaços livres e qualidade de vida urbana. Paisagem

Ambiente Ensaios, n.11, p. 279-288, 1998. 
DEMATTÊ, M.E.S.P. Princípios de paisagismo. Jaboticabal: Funep, 1997. 104p.

INSTITUTO BRASILEIRO DE GEOGRAFIA E ESTATÍSTICA - IBGE. http://

www.ibge.gov.br (31de mar. de 2002).

LIMA, A.M.L.P. Análise da arborização viária na área central e em seu entorno. 1993. 238f. Tese (Doutorado em Fitotecnia) - Escola Superior de Agronomia "Luiz de Queiroz”, Piracicaba, 1993.

LLARDENT, L. R. A. Zonas verdes y espaços livres en la ciudad. Madrid: Closas Orcoyen, 1982.538 p.

MILANO, M. S. Avaliação e análise da arborização de ruas de Curitiba. 1984. 130f. Dissertação (Mestrado em Engenharia Florestal) Universidade Federal do Paraná, Curitiba, 1984.

NUCCI, J.C. Qualidade ambiental e adensamento urbano: um estudo de ecologia e planejamento da paisagem aplicado ao distrito de Santa Cecília (MSP). São Paulo: USP, FFLCH, 2001. 236 p.

OLIVEIRA, C.H. Planejamento ambiental na cidade de São Carlos (SP) com ênfase nas áreas públicas e áreas verdes: diagnósticos e propostas. 1996. 181 f. Dissertação (Mestrado em Ecologia e Recursos Naturais) Universidade Federal de São Carlos, Carlos, 1996.
Oliveira, J.B. Solos do Estado de São Paulo: descrição das classes registradas no mapa pedológico. Campinas: Instituto Agronômico de Campinas, 1999. 112p. (IAC. Boletim Científico, 45).

OLIVEIRA, J.B. et al. Mapa pedológico do Estado de São Paulo: legenda expandida. Campinas: IAC; Rio de Janeiro: Embrapa Solos, 1999. 64p. Escala 1:100.000.

PORTO ALEGRE. Prefeitura Municipal. Secretaria Municipal de Meio Ambiente. Cartilha dos conselheiros. Porto Alegre: 2001. 13p.

SOCIEDADE BRASILEIRADE ARBORIZAÇÃO

URBANA - SBAU. "Carta a Londrina e Ibiporã". Boletim Informativo, v.3 , n.5, p.3, 1996.

SOUSA, M.A.L.B.; FIORAVANTE, A.P.; CRUZ, R.A. Levantamento e classificação das áreas verdes da zona urbana de Botucatu, SP. In: CONGRESSO BRASILEIRO SOBRE ARBORIZAÇÃO URBANA, 1., 1992, Vitória. Anais... Vitória: 1992. v.2.p.239-252.

VINHEDO. Prefeitura Municipal. Secretaria do Comércio, Indústria e Turismo. Histórico do município de Vinhedo. Vinhedo: 2000. 15p. 